\title{
A mixed integer linear programming approach to schedule the operating room
}

\author{
F. MAAROUFI \\ MARS équipe OSS \\ ENSI Manouba \\ Manouba, Tunisia \\ fetenmaaroufi@yahoo.fr
}

\author{
H. CAMUS
}

\author{
LAGIS équipe OSL \\ Ecole Centrale de Lille \\ Villeneuve d'Ascq, France \\ herve.camus@ec-lille.fr
}

\author{
MARS équipe OSS \\ ISITCom Hamam Sousse \\ Sousse, Tunisia \\ Ouajdi.Korbaa@Centraliens-Lille.org
}

\begin{abstract}
- the problem studied in this paper is to allocate and to sequence the elective operation on operating rooms (ORs). We develop a mixed integer linear programming (MILP) model to solve this problem. Decisions in this model include the allocation of operations to material resources and human resources, the starting time of them and the starting time for each surgeon. To show the efficiency of this model, we decide to compare it with a constraints programming (CP) approach. The performance of these models is tested using a benchmark of the literature. The results indicate the efficiency of the MILP model compared with the $\mathrm{CP}$ model in terms of computational time.
\end{abstract}

Keywords—health care; operating rooms; mixed integer linear programming; constraint programming

\section{INTRODUCTION}

Operating room is the most critical resources in hospitals. It is the most precious and costly resources. ORs account for approximately $40 \%$ of hospital's total expenses [3]. In addition, ORs contribute the largest amount of revenues to most hospitals [2]. However, ORs draw their importance from their potential revenues and prohibitive costs for the society, patients and health care service.

ORs center in hospital always face problems in scheduling elective operations. In fact, these problems are among the complex encountered by healthcare organization, indeed they have to take many constraints into account, in particular those related to the availability of staff, materials and financial resources. In addition, demand for operation very often overwhelms supply therefore causing long waiting times for patients and reducing their quality of life. Therefore, OR manager are interested in finding new approaches to improve their surgical suite, which has encouraged the development of research in this domain.

This paper describes the problem of scheduling a known set of elective operations to OR. The scheduling decisions include two aspects: (1) assignment of surgery to induction beds, OR, recovery beds and surgeon, and (2) the surgery sequence within each material resource. A MILP model and a CP model are built to find a daily schedule that minimizes the Makespan which represents the completion time of the last patient's operation. This objective is studied in the literature of OT scheduling by [4] and [2]. The performance of these two models is tested using a series of computational experiments based on benchmark of the literature and the results show that the MILP model is more efficient than the CP model in terms of computational times.

This paper is organized as follows. In the next section, we propose a literature review of the OR scheduling and we identify our contribution. A MILP model and a CP model are proposed in section 3 . Section 4 compares the computational performance of the two proposed models. Finally, the paper ends with concluding remarks and future research prospects in section 5 .

\section{LITERATURE REVIEW}

The OR daily scheduling problem studied in this paper consists of allocation elective operations on human and material resources and sequencing them within each material resource within a day planning horizon. Due to the high complexity of these two components, there are many papers ([1], [6], [9], [10] and [12]) decompose the problem in two sub problems: assignment operations and sequencing operations. In this paper, we address the studies which directly focus on deterministic programming approach and combining the allocation and sequencing phases in the same problem.

Mathematical programming models, especially integer and mixed integer programming, are the most approaches used in the literature to solve the OR scheduling problem. [7] Propose an integer linear programming (ILP) model to schedule a real case of elective operations from the waiting list on a weekly time horizon with the objective of maximizing the use of the surgical suite. The aim of the purposed model is to employ more efficiently the resources installed in the surgical suite of the hospital. [2] Investigate the deterministic daily scheduling of surgical case problem. A new MIP is presented with the objective of minimizing the total idle times of ORs and the Makespan. With the MIP model, the authors determine the allocation of resources and the sequence of operations within OR and the start time of them. [5] Develop a mathematical programming approach to solve the surgical operations scheduling problem. They propose a MILP model to minimize the number of unscheduled surgical operation. The proposed model takes into account the constraints of human (surgeons) and material (ORs) resources. There are others papers propose a mathematical programming approaches and compare their performance with heuristics approaches, for instance [12] Use a RCPSP (Resource Constraint Project Scheduling Problem) to generate scheduling and planning of the surgical operations while focusing as much attention on human resources (surgeons) as on economic factors. They develop a MIP model 
including the planning and scheduling problem. They compare the results of MIP with a heuristic solution procedure based on genetic algorithm. [4] Investigate the deterministic daily scheduling operating rooms problem for elective patient. They propose a constraint programming model to solve their problem taking into account some constraints on human (surgeons) and material (OR and recovery bed) resources and they compare the CP model with a MILP model.

Although these papers study the allocation and sequencing phases and resolve with mathematical programming approach, we cannot use those approaches because all of these assume that the human resources (surgeons) are already known in advance (i.e. the allocation of the human resources to operation is known) to reduce the complexity of the problem and in our approaches the allocation of the human resources (surgeons) are unknown. In addition, in this paper the operating theatre (OT) composes of induction beds, ORs and recovery beds; while these previous papers focus on the OR orland the recovery beds. The new structure of the OT is studied in [6] but the authors resolve the allocation problem with heuristic approach and propose a MILP model to sequence the operations into material resources.

The contributions made in this study are follows: we model the deterministic OT scheduling problem, integrating allocation and sequencing decisions in the same model; we consider surgeons, nurses, induction beds, ORs as well as recovery beds, as resources and we provide a more realistic model of the surgery process by explicitly considering the induction, the operations and the recovery tasks.

\section{PROBLEM DEFINITION}

Many paper focus on the ORs and recovery room when discussing OT scheduling problem. Furthermore, induction task is always performed in the OR. The contribution of the paper is to separate the induction and the operation task to improve the use of the ORs. With the new structure of the OT, the goal is to perform the induction task in induction room while the OR is prepared for another operation.

A MILP model is proposed to minimize the Makespan of the OT. To show the efficiency of the MILP model, we develop a CP model and we compare the results of the MILP with the CP model. Here are the notations used for the two proposed models.

TABLE I. NOTATIONS

\begin{tabular}{|l|l|}
\hline $\mathrm{O}$ & The total number of operation \\
\hline $\mathrm{R}$ & The total number of ORs \\
\hline $\mathrm{IB}$ & The total number of induction beds \\
\hline $\mathrm{B}$ & The total number of recovery beds \\
\hline $\mathrm{S}$ & The total number of surgeons \\
\hline $\mathrm{NM}$ & The number of nurses available for an operation in OR \\
\hline $\mathrm{NR}$ & The total number of nurses $\mathbf{n r}$ \\
\hline $\mathrm{R}_{\mathrm{s}}$ & The set of rooms preferred by the surgeon $\mathbf{s}$ \\
\hline $\mathrm{O}_{\mathrm{s}}$ & The set of operation preferred by the surgeon $\mathbf{s}$ \\
\hline $\mathrm{RAT}_{\mathrm{r}}$ & Regular Available Time for OR $\mathbf{r}$ \\
\hline $\mathrm{RATS}_{\mathrm{s}}$ & Regular Available Time for Surgeon $\mathbf{s}$ \\
\hline $\mathrm{pIb}_{\mathrm{o}}$ & Duration of induction of operation o \\
\hline $\mathrm{p}_{\mathrm{o}}$ & Duration of operation $\mathbf{o}$ \\
\hline $\mathrm{pI}_{\mathrm{o}}$ & Induction time of operation o in the OR \\
\hline
\end{tabular}

\begin{tabular}{|l|l|}
\hline $\mathrm{pb}_{\mathrm{o}}$ & Duration of recovery of operation o \\
\hline $\mathrm{tr}$ & OR turnover time between two consecutive operations \\
\hline $\mathrm{ts}$ & Surgeon turnover time between two consecutive operations \\
\hline $\operatorname{Pre}_{\mathrm{tp}, \mathrm{r}}$ & Operation of type tp is operated in the room $\mathbf{r}$ \\
\hline
\end{tabular}

\section{A. a MILP model}

This section describes the MILP model for determining the daily surgical scheduling of electives patients. Let $\left[A_{s}, B_{s}\right]$ represents the interval surgeons availability. Each surgeon $\mathbf{s}$ expresses her/his availability which can operate on day; such as $B_{s}-A_{s}=R A T S_{s}$. A solution to the schedule problem is given by means of integer and binary variables.

TABLE II. DECISION VARIABLES OF MILP MODEL

\begin{tabular}{|c|c|}
\hline \multicolumn{2}{|r|}{ Integer variables } \\
\hline $\mathrm{SO}_{\mathrm{o}}$ & Starting time of operation o \\
\hline $\mathrm{SI}_{\mathrm{o}}$ & Starting time of induction of operation o \\
\hline $\mathrm{SB}_{\mathrm{o}}$ & Starting time of recovery of operation o \\
\hline$\Delta_{\mathrm{o}}$ & Duration of recovery of operation o in OR \\
\hline $\mathrm{S}_{\mathrm{s}}$ & Starting time of surgeon $\mathrm{s}$ \\
\hline \multicolumn{2}{|r|}{ Binary variables } \\
\hline $\mathrm{Z}_{\mathrm{o}, \mathrm{p}, \mathrm{lb}}$ & $\begin{array}{l}1 \text { if operation o starts before operation } \mathrm{p} \text { in the induction } \\
\text { bed } \mathrm{Ib}\end{array}$ \\
\hline$\Theta_{0, p, r}$ & 1 if operation o starts before operation $\mathrm{p}$ in the $\mathrm{OR} \mathrm{r}$ \\
\hline$\alpha_{o, p, b}$ & $\begin{array}{l}1 \text { if operation o starts before operation } \mathrm{p} \text { in the recovery bed } \\
\mathrm{b}\end{array}$ \\
\hline $\mathrm{y}_{\mathrm{o}, \mathrm{p}, \mathrm{s}}$ & $\begin{array}{l}1 \text { if operation o starts before operation } \mathrm{p} \text { in the operation list } \\
\text { of surgeon } \mathrm{s}\end{array}$ \\
\hline $\mathrm{IB}_{\mathrm{o}, \mathrm{Ib}}$ & 1 if the operation o assigned to the induction bed $\mathrm{Ib}$ \\
\hline $\mathrm{RB}_{\mathrm{o}, \mathrm{b}}$ & 1 if the operation o assigned to the recovery bed $\mathrm{b}$ \\
\hline $\mathrm{OR}_{\mathrm{o}, \mathrm{r}}$ & 1 if the operation o assigned to the OR $\mathrm{r}$ \\
\hline $\mathrm{NUR}_{\mathrm{o}, \mathrm{nr}}$ & 1 if the operation o assigned to the nurse $\mathrm{nr}$ \\
\hline $\mathrm{SUR}_{\mathrm{o}, \mathrm{s}}$ & 1 if the operation o assigned to the surgeon $\mathrm{s}$ \\
\hline $\mathrm{W}_{\mathrm{nr}, \mathrm{r}}$ & 1 if the nurse $\mathbf{n r}$ is assigned to OR $\mathbf{r}$ \\
\hline
\end{tabular}

A MILP model is then formulated as follows:

$$
\begin{gathered}
\mathrm{obj}=\min \left(\max \left(\mathrm{SB}_{\mathrm{o}}+\mathrm{pb}_{\mathrm{o}}-\Delta_{\mathrm{o}}\right)\right) \\
\sum_{\mathrm{o}=1}^{\mathrm{O}} \mathrm{p}_{\mathrm{o}} \times \mathrm{OR}_{\mathrm{o}, \mathrm{r}} \leq \mathrm{RAT}_{\mathrm{r}} \forall \mathrm{r} \in\{1 . . \mathrm{R}\} \\
\sum_{\mathrm{o}=1}^{\mathrm{Os}_{\mathrm{o}}} \mathrm{p}_{\mathrm{o}} \times \mathrm{SUR}_{\mathrm{o}, \mathrm{s}} \leq \mathrm{RATS}_{\mathrm{s}} \forall \mathrm{s} \in\{1 . . \mathrm{S}\} \\
\sum_{\mathrm{r}=1}^{\mathrm{R}} \mathrm{OR}_{\mathrm{o}, \mathrm{r}}=1 \forall \mathrm{o} \in\{1 . . \mathrm{O}\} \\
\sum_{\mathrm{lb}=1}{ }^{\mathrm{IB}} \mathrm{IB}_{\mathrm{o}, \mathrm{Ib}} \leq 1 \forall \mathrm{o} \in\{1 . . \mathrm{O}\} \\
\sum_{\mathrm{b}=1}^{\mathrm{B}} \mathrm{RB}_{\mathrm{o}, \mathrm{b}} \leq 1 \forall \mathrm{o} \in\{1 . . \mathrm{O}\} \\
\sum_{\mathrm{nr}=1}^{\mathrm{NR}} \mathrm{NUR}_{\mathrm{o}, \mathrm{nr}} \geq \mathrm{NM} \forall \mathrm{o} \in\{1 . . \mathrm{O}\} \\
\sum_{\mathrm{r}=1}^{\mathrm{R}} \mathrm{W}_{\mathrm{nr}, \mathrm{r}} \leq 1 \forall \mathrm{nr} \in\{1 . . \mathrm{NR}\}
\end{gathered}
$$


$\mathrm{W}_{\mathrm{nr}, \mathrm{r}} \geq 1-\mathrm{M} \times\left(2-\mathrm{OR}_{\mathrm{o}, \mathrm{r}}-\mathrm{NUR}_{\mathrm{onr}}\right) \forall \mathrm{o} \epsilon\{1 . . \mathrm{O}\}, \mathrm{nr} \epsilon$ $\{1 . . \mathrm{NR}\}$

$$
\sum_{\mathrm{o}=1}^{\mathrm{O}} \sum_{\mathrm{tp}=1}{ }^{\mathrm{Type}} \sum_{\mathrm{r}=1}^{\mathrm{R}} \mathrm{OR}_{\mathrm{o}, \mathrm{r}} \times \text { pre }_{\mathrm{tp}, \mathrm{r}}=\mathrm{O}
$$$$
\theta_{\mathrm{o}, \mathrm{p}, \mathrm{r}}+\theta_{\mathrm{p}, \mathrm{o}, \mathrm{r}} \leq \mathrm{OR}_{\mathrm{o}, \mathrm{r}} \forall \mathrm{o}, \mathrm{p} \in\{1 . . \mathrm{O}\}, \mathrm{o}<\mathrm{p}, \mathrm{r} \in\{1 . . \mathrm{R}\}
$$

$$
\theta_{\mathrm{o}, \mathrm{p}, \mathrm{r}}+\theta_{\mathrm{p}, \mathrm{o}, \mathrm{r}} \leq \mathrm{OR} \mathrm{R}_{\mathrm{p}, \mathrm{r}} \forall \mathrm{o}, \mathrm{p} \in\{1 . . \mathrm{O}\}, \mathrm{o}<\mathrm{p}, \mathrm{r} \in\{1 . . \mathrm{R}\}(1.12)
$$

$$
\theta_{o, p, r}+\theta_{p, o, r} \geq \mathrm{OR}_{\mathrm{o}, \mathrm{r}}+\mathrm{OR}_{\mathrm{p}, \mathrm{r}}-1 \forall \mathrm{o}, \mathrm{p} \in\{1 . . \mathrm{O}\}, \mathrm{o}<\mathrm{p}, \mathrm{r} \in\{1 . . \mathrm{R}\}
$$

$$
\mathrm{z}_{\mathrm{o}, \mathrm{p}, \mathrm{lb}}+\mathrm{z}_{\mathrm{p}, \mathrm{o}, \mathrm{Ib}} \leq \mathrm{IB}_{\mathrm{o}, \mathrm{Ib}} \forall \mathrm{o}, \mathrm{p} \in\{1 . . \mathrm{O}\}, \mathrm{o}<\mathrm{p}, \mathrm{Ib} \in\{1 . . \mathrm{IB}\}
$$

$$
\mathrm{z}_{\mathrm{o}, \mathrm{p}, \mathrm{Ib}}+\mathrm{z}_{\mathrm{p}, \mathrm{o}, \mathrm{Ib}} \leq \mathrm{IB}_{\mathrm{p}, \mathrm{Ib}} \forall \mathrm{o}, \mathrm{p} \in\{1 . . \mathrm{O}\}, \mathrm{o}<\mathrm{p}, \mathrm{Ib} \in\{1 . . \mathrm{IB}\}
$$

$$
\mathrm{z}_{\mathrm{o}, \mathrm{p}, \mathrm{Ib}}+\mathrm{z}_{\mathrm{p}, \mathrm{o}, \mathrm{Ib}} \geq \mathrm{IB}_{\mathrm{o}, \mathrm{Ib}}+\mathrm{IB}_{\mathrm{p}, \mathrm{Ib}}-1 \forall \mathrm{o}, \mathrm{p} \in\{1 . . \mathrm{O}\}, \mathrm{o}<\mathrm{p}, \mathrm{Ib} \epsilon
$$
$\{1 . . \mathrm{IB}\}$

$\alpha_{o, p, b}+\alpha_{p, o, b} \leq R_{0, b} o, p \in\{1 . . O\}, o<p, b \in\{1 . . B\}$

$$
\alpha_{o, p, b}+\alpha_{p, o, b} \leq R_{p, b} \forall o, p \in\{1 . . \mathrm{O}\}, o<p, b \in\{1 . . B\}(1.18)
$$

$$
\mathrm{y}_{\mathrm{o}, \mathrm{p}, \mathrm{s}}+\mathrm{y}_{\mathrm{p}, \mathrm{o}, \mathrm{s}} \leq \mathrm{SUR}_{\mathrm{o}, \mathrm{s}} \forall \mathrm{o}, \mathrm{p} \in\{1 . . \mathrm{O}\}, \mathrm{o}<\mathrm{p}, \mathrm{s} \in\{1 . . \mathrm{S}\}
$$

$$
\mathrm{y}_{\mathrm{o}, \mathrm{p}, \mathrm{s}}+\mathrm{y}_{\mathrm{p}, \mathrm{o}, \mathrm{s}} \leq \mathrm{SUR}_{\mathrm{o}, \mathrm{s}} \forall \mathrm{o}, \mathrm{p} \in\{1 . . \mathrm{O}\}, \mathrm{o}<\mathrm{p}, \mathrm{s} \in\{1 . . \mathrm{S}\}
$$

$$
\{1 . . \mathrm{S}\}
$$

$$
\begin{gathered}
\mathrm{SI}_{\mathrm{o}}+\mathrm{pI}_{\mathrm{o}}=\mathrm{SO}_{\mathrm{o}} \forall \mathrm{o} \in\{1 . . \mathrm{O}\} \\
\mathrm{SO}_{\mathrm{o}}+\mathrm{pIr}_{\mathrm{o}}+\mathrm{p}_{\mathrm{o}}+\Delta_{\mathrm{o}}=\mathrm{SB}_{\mathrm{o}} \forall \mathrm{o} \epsilon\{1 . . \mathrm{O}\}
\end{gathered}
$$

$\mathrm{SI}_{\mathrm{p}} \geq \mathrm{SI}_{\mathrm{o}}+\mathrm{pI}_{\mathrm{o}}-\mathrm{M} \times\left(3-\mathrm{z}_{\mathrm{o}, \mathrm{p}, \mathrm{Ib}}-\mathrm{IB}_{\mathrm{o}, \mathrm{Ib}}-\mathrm{IB}_{\mathrm{p}, \mathrm{Ib}}\right) \forall \mathrm{o}, \mathrm{p} \in\{1 . . \mathrm{O}\}$, $\mathrm{o} \neq \mathrm{p}, \mathrm{Ib} \in\{1 . . \mathrm{IB}\}$

$\mathrm{SO}_{\mathrm{p}} \geq \mathrm{SO}_{\mathrm{o}}+\mathrm{pIr}_{\mathrm{o}}+\mathrm{p}_{\mathrm{o}}+\operatorname{tr}+\Delta_{\mathrm{o}}-\mathrm{M} \times\left(3-\theta_{\mathrm{o}, \mathrm{p}, \mathrm{r}}-\mathrm{OR}_{\mathrm{o}, \mathrm{r}}-\right.$ $\left.\mathrm{OR}_{\mathrm{p}, \mathrm{r}}\right) \forall \mathrm{o}, \mathrm{p} \in\{1 . . \mathrm{O}\}, \mathrm{o} \neq \mathrm{p}, \mathrm{r} \in\{1 . . \mathrm{R}\}$

$\mathrm{SB}_{\mathrm{p}} \geq \mathrm{SB}_{\mathrm{o}}+\mathrm{pb}_{\mathrm{o}}-\Delta_{\mathrm{o}}-\mathrm{M} \times\left(3-\alpha_{\mathrm{o}, \mathrm{p}, \mathrm{r}}-\mathrm{RB}_{\mathrm{o}, \mathrm{b}}-\mathrm{RB}_{\mathrm{p}, \mathrm{b}}\right) \forall \mathrm{o}, \mathrm{p} \epsilon$ $\{1 . . \mathrm{O}\}, \mathrm{o} \neq \mathrm{p}, \mathrm{b} \in\{1 . . \mathrm{B}\}$

$\mathrm{SO}_{\mathrm{p}} \geq \mathrm{SO}_{\mathrm{o}}+\mathrm{pIr}_{\mathrm{o}}+\mathrm{p}_{\mathrm{o}}+\operatorname{tr}+\Delta_{\mathrm{o}}-\mathrm{M} \times\left(3-\theta_{\mathrm{o}, \mathrm{p}, \mathrm{r}}-\mathrm{NUR}_{\mathrm{on}, \mathrm{r}}-\right.$ $\left.\mathrm{NUR}_{\mathrm{pn}, \mathrm{r}}\right) \forall \mathrm{o}, \mathrm{p} \in\{1 . . \mathrm{O}\}, \mathrm{o} \neq \mathrm{p}$, nre $\{1 . . \mathrm{NR}\}$

$$
\mathrm{SO}_{\mathrm{o}} \geq \mathrm{S}_{\mathrm{s}}-\mathrm{M} \times\left(1-\mathrm{SUR}_{\mathrm{o}, \mathrm{S}}\right) \forall \mathrm{o} \in\{1 . . \mathrm{O}\}, \mathrm{s} \in\{1 . . \mathrm{S}\}(1.29)
$$

$\begin{aligned} & \mathrm{SO}_{\mathrm{p}}+\mathrm{pIr}_{\mathrm{p}} \geq \mathrm{SO}_{\mathrm{o}}+\mathrm{pIr}_{\mathrm{o}}+\mathrm{p}_{\mathrm{o}}+\mathrm{ts}-\mathrm{M} \times\left(3-\mathrm{y}_{\mathrm{o}, \mathrm{p}, \mathrm{s}}-\mathrm{SUR}_{\mathrm{o}, \mathrm{s}}-\right. \\ &\left.\mathrm{SUR}_{\mathrm{p}, \mathrm{s}}\right) \forall \mathrm{o}, \mathrm{p} \in \mathrm{O}_{\mathrm{s}}, \mathrm{o} \neq \mathrm{p}, \mathrm{s} \in\{1 . . \mathrm{S}\}\end{aligned}$

$$
\mathrm{SO}_{\mathrm{o}}+\mathrm{pIr}_{\mathrm{o}}+\mathrm{p}_{\mathrm{o}}-\mathrm{M} \times\left(1-\mathrm{SUR}_{\mathrm{o}, \mathrm{s}}\right) \leq \mathrm{B}_{\mathrm{s}} \forall \mathrm{o} \in \mathrm{O}_{\mathrm{s}}, \mathrm{s} \in\{1 . . \mathrm{S}\}
$$

$$
\mathrm{SO}_{\mathrm{o}}+\mathrm{pIr}_{\mathrm{o}} \geq \mathrm{A}_{\mathrm{s}} \times \mathrm{SUR}_{\mathrm{o}, \mathrm{s}} \forall \mathrm{o} \in \mathrm{O}_{\mathrm{s}}, \mathrm{s} \in\{1 . . \mathrm{S}\}
$$

$\mathrm{w}_{\mathrm{nr}, \mathrm{r}}, \mathrm{OR}_{\mathrm{o}, \mathrm{r}}, \mathrm{IB}_{\mathrm{o}, \mathrm{Ib}}, \mathrm{RB}_{\mathrm{o}, \mathrm{b}}, \mathrm{NUR}_{\mathrm{o}, \mathrm{nr}}, \mathrm{SUR}_{\mathrm{o}, \mathrm{s}} \in\{0,1\} \forall \mathrm{o} \epsilon$ $\{1 . . \mathrm{O}\}, \mathrm{s} \in\{1 . . \mathrm{S}\}, \mathrm{r} \in\{1 . . \mathrm{R}\}, \mathrm{nr} \in\{1 . . \mathrm{NR}\}, \mathrm{Ib} \in\{1 . . \mathrm{IB}\}, \mathrm{b} \in$ $\{1 . . \mathrm{B}\}$

$$
\mathrm{SO}_{\mathrm{o}}, \mathrm{SI}_{\mathrm{o}}, \mathrm{SB}_{\mathrm{o}}, \mathrm{S}_{\mathrm{s}} \geq 0 \forall \mathrm{o} \in\{1 . . \mathrm{O}\}, \mathrm{s} \in\{1 . . \mathrm{S}\}
$$

The criterion obj to optimize is the maximum completion time for operation in the OT. In order to obtain the most balanced operation schedule with smaller amount of opening hours in the OT on the day, we employ the Makespan of the OT. Constraints (1.4) ensure that an operation can be assigned to an OR only if it is opened and each operation is assigned to exactly one OR, respectively. Constraints sets (1.2) - (1.3) impose a daily operating time limit on each OR and surgeon. Constraints $(1.5)-(1.6)$ ensure that each operation should be assigned to at most one induction bed and one recovery bed. Constraints (1.7) impose the minimal number of nurses who can participate in one operation. Constraints (1.8) and (1.9) ensure that a nurse does not overlap between operating rooms during the day. Constraints (1.10) are related to OR accessibility and verify that the operations happen in an appropriate OR.

A precedence relation exists between two operations if and only if they are assigned to the same OR (resp. induction beds, recovery beds, surgeons). This is enforced by constraints (1.11) - (1.22). The set of the constraints (1.23) and (1.24) define the 
precedence constraints. Constraints (1.25) and (1.27) ensure that an induction bed and a recovery bed cannot be occupied by more than one patient in the same time. The constraints (1.26) imply that an OR cannot be occupied by more than one patient. Constraints (1.28) verify that a nurse cannot participate in more than one operation at the same time. Constraints (1.30) ensure that a surgeon cannot operate more than one patient at the same time. Constraints $(1.25)-(1.30)$ make sure that two operations do not overlap in time if their assigned resource (OR or surgeon or nurse) is the same. Observe that the constraints (1.26) are inutile if the operating room $r$ is not assigned to o and $\mathrm{p}$, respectively, since then $\theta_{\mathrm{o}, \mathrm{p}, \mathrm{r}}+\mathrm{OR}_{\mathrm{o}, \mathrm{r}}+\mathrm{OR}_{\mathrm{p}, \mathrm{r}} \leq 1$ and hence $\mathrm{M}\left(3-\theta_{\mathrm{o}, \mathrm{p}, \mathrm{r}}-\mathrm{OR}_{\mathrm{o}, \mathrm{r}}-\mathrm{OR}_{\mathrm{p})}\right.$ is greater than the left-hand side because of a very large value of $M$. If the operating room $r$ is assigned to $o$ and $p$ then the constraints (1.15) are necessary, depending on whether $\theta_{\mathrm{o}, \mathrm{p}, \mathrm{r}}=1$ or $\theta_{\mathrm{o}, \mathrm{p}, \mathrm{r}}=0$. For instance $\theta_{\mathrm{o}, \mathrm{p}, \mathrm{r}}=1$, constraints (1.15) say that the operation $\mathrm{p}$ starts after the completion time of operation o with a minimum time tr (cleaning time of OR). The M parameter used is an upper bound on the surgery completion time, this value is sufficient to keep the constraints (1.25) - (1.31) inutile when necessary. Constraints (1.29) ensure that operation of a surgeon cannot be started before his or her arrival to the surgical suite. Constraints (1.19) ensure that the starting time of each operation cannot be more than the daily regular availability. Constraints (1.31) and (1.32) ensure that each surgeon operates during the interval of time in which he/she is available. Finally, the constraints (1.33) and (1.34) express the variables' domain.

\section{B. a CP model}

This section presents the CP model we build for solving the elective scheduling problem. In this model, time has a discrete representation as a set of time periods available for scheduling, $\{1 \ldots \mathbf{T}\}$. This representation of time is used in the literature such as [4] and [12] when they solve the scheduling problem with the CP mechanism. Let $S A(s, t, r)$ represents the matrix surgeons availability. Each surgeon s expresses her/ his availability in time slot $\mathbf{t}$ in preference room $\mathbf{r} \in \mathbf{R s}$; which represents the set of preference room of surgeons. Before formulating the problem, we define the set of binary variables:

TABLE III. DECISION VARIABLES OF CP MODEL

\begin{tabular}{|l|l|}
\hline $\mathrm{OR}_{\mathrm{o}, \mathrm{r}, \mathrm{t}}$ & $\begin{array}{l}1 \text { if operation o starts in the OR } \mathrm{r} \text { at } \\
\text { time slots } \mathrm{t}\end{array}$ \\
\hline $\mathrm{IB}_{\mathrm{o}, \mathrm{Ib}, \mathrm{t}}$ & $\begin{array}{l}1 \text { if operation o starts in the } \\
\text { induction bed Ib at time slots } \mathrm{t}\end{array}$ \\
\hline $\mathrm{RB}_{\mathrm{o}, \mathrm{b}, \mathrm{t}}$ & $\begin{array}{l}1 \text { if operation o starts in the recovery } \\
\text { bed b at time slots t }\end{array}$ \\
\hline $\mathrm{SUR}_{\mathrm{o}, \mathrm{s}, \mathrm{t}}$ & $\begin{array}{l}1 \text { if operation o is performed by } \\
\text { surgeon s at time slots t }\end{array}$ \\
\hline $\mathrm{NUR}_{\mathrm{o}, \mathrm{nr}, \mathrm{t}}$ & $\begin{array}{l}1 \text { if operation o is assigned to nurse } \\
\text { nr at time slots t }\end{array}$ \\
\hline
\end{tabular}

The CP model is then formulated as follows:

$$
\sum_{\mathrm{o}=1}^{\mathrm{O}} \sum_{\mathrm{t}=1}^{\mathrm{T}} \mathrm{p}_{\mathrm{o}} \times \mathrm{OR}_{\mathrm{or}, \mathrm{t}} \leq \mathrm{RAT}_{\mathrm{r}} \forall \mathrm{r} \in\{1 . . \mathrm{R}\}
$$

$$
\sum_{\mathrm{o}=1} \mathrm{O}_{\mathrm{s}} \sum_{\mathrm{t}=1}^{\mathrm{T}} \mathrm{p}_{\mathrm{o}} \times \mathrm{SUR}_{\mathrm{o}, \mathrm{s}, \mathrm{t}} \leq \mathrm{RATS}_{\mathrm{s}} \forall \mathrm{s} \in\{1 . . \mathrm{S}\}
$$

$\{1 . . T\}$

$\sum_{\mathrm{o}=1}^{\mathrm{O}} \sum_{\tau=\mathrm{t}}^{\min \left(\mathrm{t}+\underset{\mathrm{o}}{\mathrm{p}}+\underset{\mathrm{o}}{\mathrm{prr}}+\Delta_{\mathrm{o}}+\mathrm{tr}-1, \mathrm{~T}\right)} \mathrm{OR}_{\mathrm{o}, \mathrm{r}, \tau} \leq 1 \forall \mathrm{r} \in\{1 . . \mathrm{R}\}, \mathrm{t} \epsilon$

$$
\sum_{\mathrm{o}=1}^{\mathrm{O}} \sum_{\mathrm{s}} \sum_{\tau=\mathrm{t}} \min \left(\mathrm{t}+\mathrm{p}_{\mathrm{o}}+\mathrm{ts}-1, \mathrm{~T}\right) \mathrm{SUR}_{\mathrm{o}, \mathrm{s}, \tau} \leq 1 \forall \mathrm{s} \in\{1 . . \mathrm{S}\}, \mathrm{t} \in\{1 . . \mathrm{T}\}
$$

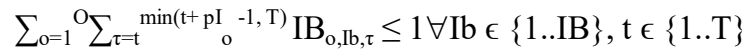

$$
\sum_{\mathrm{o}=1}^{\mathrm{O}} \sum_{\tau=\mathrm{t}}^{\min \left(\mathrm{t}+\mathrm{pb}_{\mathrm{o}}-\Delta_{\mathrm{o}}-1, \mathrm{~T}\right)} \mathrm{RB}_{\mathrm{o}, \mathrm{b}, \tau} \leq 1 \forall \mathrm{b} \in\{1 . . \mathrm{B}\}, \mathrm{t} \in\{1 . . \mathrm{T}\}
$$

$$
\sum_{\mathrm{r}=1}^{\mathrm{R}} \sum_{\mathrm{t}=1}^{\mathrm{T}} \mathrm{OR}_{\mathrm{o}, \mathrm{r}, \mathrm{t}}=1 \quad \forall \mathrm{o} \in\{1 . . \mathrm{O}\}
$$

$$
\sum_{\mathrm{Ib}=1}^{\mathrm{IB}} \sum_{\mathrm{t}=1}^{\mathrm{T}} \mathrm{IB}_{\mathrm{o}, \mathrm{lb}, \mathrm{t}} \leq 1 \quad \forall \mathrm{o} \in\{1 . . \mathrm{O}\}
$$

$$
\sum_{\mathrm{b}=1}^{\mathrm{B}} \sum_{\mathrm{t}=1}^{\mathrm{T}} \mathrm{RB}_{\mathrm{o}, \mathrm{b}, \mathrm{t}} \leq 1 \quad \forall \mathrm{o} \in\{1 . . \mathrm{O}\}
$$

$$
\sum_{\mathrm{nr}=1}{ }^{\mathrm{NR}} \sum_{\mathrm{t}=1}^{\mathrm{T}} \mathrm{NUR}_{\mathrm{o}, \mathrm{nr}, \mathrm{t}} \geq \mathrm{NM} \forall \mathrm{o} \in\{1 . . \mathrm{O}\}
$$

$$
\sum_{\mathrm{t}=1}^{\min (\mathrm{t}+\underset{\mathrm{o}}{\mathrm{pI}}-1, \mathrm{~T})} \sum_{\mathrm{lb}=1}^{\mathrm{IB}}(\mathrm{t}+\mathrm{pIo}) \times \mathrm{IB}_{\mathrm{o}, \mathrm{lb}, \mathrm{t}} \leq \sum_{\mathrm{t}=1}^{\mathrm{T}} \sum_{\mathrm{r}=1}^{\mathrm{R}} \mathrm{t} \times
$$
$\mathrm{OR}_{\mathrm{o}, \mathrm{r}, \mathrm{t}} \forall \mathrm{o} \in\{1 . . \mathrm{O}\}$

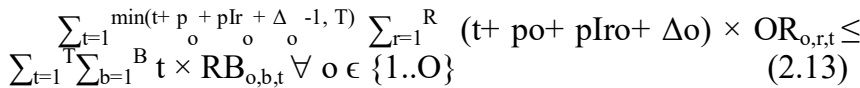

$\sum_{\mathrm{o}=1}^{\mathrm{O}} \sum_{\mathrm{s} \tau=\mathrm{t}} \min \left(\mathrm{t}+\mathrm{p}_{\mathrm{o}}^{-1, \mathrm{~T})} \mathrm{OR}_{\mathrm{o}, \mathrm{r}, \tau} \leq \mathrm{SA}(\mathrm{s}, \mathrm{t}, \mathrm{r}) \forall \mathrm{s} \in\{1 . . \mathrm{S}\}, \mathrm{t} \epsilon\right.$

$$
\begin{aligned}
& \sum_{\mathrm{o}=1}^{\mathrm{O}} \mathrm{s} \sum_{\tau=\mathrm{t}} \min \left(\mathrm{t}+\mathrm{p}_{\mathrm{o}}^{-1, \mathrm{~T})} \mathrm{OR}_{\mathrm{o}, \mathrm{r}, \tau}=\sum_{\mathrm{o}=1} \mathrm{O}_{\mathrm{s}} \sum_{\tau=\mathrm{t}} \min \left(\mathrm{t}+\mathrm{p}_{\mathrm{o}}{ }^{-1, T)} \mathrm{SUR}_{\mathrm{o}, \mathrm{s}, \tau}\right.\right. \\
& \forall \mathrm{S} \in\{1 . . \mathrm{S}\}, \mathrm{t} \in\{1 . . \mathrm{T}\}, \mathrm{r} \in \mathrm{R}_{\mathrm{S}}
\end{aligned}
$$

$$
\mathrm{SUR}_{\mathrm{o}, \mathrm{s}, \mathrm{t}}=0 \forall \mathrm{o} \in\{1 . . \mathrm{O}\} \backslash \mathrm{O}_{\mathrm{s}}, \mathrm{S} \in\{1 . . \mathrm{S}\}, \mathrm{t} \in\{1 . . \mathrm{T}\}
$$

$\sum_{\mathrm{t}=1}^{\mathrm{T}} \mathrm{OR}_{\mathrm{o}, \mathrm{r}, \mathrm{t}} \leq \operatorname{pre}_{\mathrm{r}, \mathrm{tp}} \forall \mathrm{O} \in\{1 . . \mathrm{O}\}, \mathrm{r} \in\{1 . . \mathrm{R}\}$, tp $\epsilon$ $\{1 . . \mathrm{TYPE}\}$

$$
\sum_{\mathrm{o}=1}^{\mathrm{O}} \sum_{\mathrm{t}=1}^{\mathrm{T}}\left(\mathrm{t}+\mathrm{pb}_{\mathrm{o}}\right) \times \mathrm{RB}_{\mathrm{o}, \mathrm{b}, \mathrm{t}} \leq \mathrm{T} \forall \mathrm{b} \in\{1 . . \mathrm{B}\}
$$




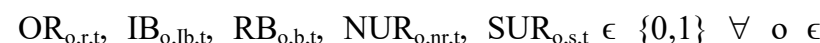
$\{1 . . \mathrm{O}\}, \mathrm{r} \in\{1 . . \mathrm{R}\}, \mathrm{s} \in\{1 . . \mathrm{S}\}, \mathrm{b} \in\{1 . . \mathrm{B}\}, \mathrm{Ib} \in\{1 . . \mathrm{IB}\}, \mathrm{t} \in\{1 . . \mathrm{T}\}$

Here, constraints sets (2.2) and (2.3) impose a daily operating time limit on each OR and surgeon. Constraints (2.4) (resp. (2.6) and (2.7)) prevent the assignment of several overlapping operations in the same room (resp. the same induction bed and the same recovery bed). These constraints also present $t r$ empty periods for room cleaning at the end of each operation. The set of constraints (2.5) guarantees that a surgeon is assigned to at most one operation at any time. The surgeons may exchange operating rooms. This exchange allows surgeons to work in another OR during hygiene periods in the previous room (about $15 \mathrm{~min}$ idle). This is also the reason why the cleaning time is not incorporated in the operations' duration. Constraints (2.8) ensure that an operation begins once and only once. Constraints (2.11) express that there are at least NM nurses in per operation. The constraints (2.9) (resp. 2.10) ensure that only one operation can stay in the induction bed (resp. recovery bed) at time slots $t$. The precedence constraints are described in the set of constraints $((2.12)-(2.13))$. In constraints (2.14) every surgeon expresses her/his preference and the availabilities for certain time slots, the availability is presented by the matrix $S A(s, t, r)$. Constraints (2.15) verify that the surgeon cannot be in two ORs by the same time. Constraints (2.16) ensure that the surgeons perform the preference operations. Constraints (2.17) are related to OR accessibility and verify that the operations happen in an appropriate ORs. The set of constraints (2.18) bound the limited capacity for OT in number of available hours. Constraints (2.19) express the variables' domains.

\section{EXPERIMENTAL RESULTS}

This section presents a comparison between both proposed models described in section 3. These two models are implemented under Windows 8 with an Intel ${ }^{\circledR}$ Celeron ${ }^{\circledR} 1.4$ $\mathrm{GHz}$ processor and 4.0 GB RAM. The MILP model is solved using IBM-ILOG-CPLEX 12.2. The CP model is based on the constraint programming method. It is solved by the solver included in the Java library CHOCO 3.0.0 using JDK 1.8. $\mathrm{CHOCO}$ is a library for constraint satisfaction problems (CSP) and $\mathrm{CP}$ and is based on a mechanism of propagation of instantiation with structures which use a "backtracking" algorithm. This solver is used by [4] and [8] for solving OR scheduling problem using a CP mechanism. These two models are evaluated by solving several problem instances described in Table IV where $\mathrm{O}$ denotes the number of operations and $\mathrm{R}, \mathrm{S}$, $\mathrm{IB}$ and $\mathrm{B}$ represent respectively the number of OR, surgeons, induction beds and recovery beds.

TABLE IV. CHARACTERISTICS OF PROBLEM INSTANCES

\begin{tabular}{|l|l|l|l|l|l|}
\hline $\begin{array}{c}\text { Instances } \\
\mathbf{N}^{\circ}\end{array}$ & \multicolumn{1}{|c|}{$\mathbf{O}$} & $\mathbf{R}$ & IB & B \\
\hline Inst.1 & 9 & 4 & 6 & 6 & 6 \\
\hline Inst.2 & 11 & 4 & 6 & 6 & 6 \\
\hline Inst.3 & 13 & 4 & 6 & 6 & 6 \\
\hline Inst.4 & 15 & 4 & 6 & 6 & 6 \\
\hline Inst.5 & 11 & 6 & 9 & 9 & 9 \\
\hline Inst.6 & 13 & 6 & 9 & 9 & 9 \\
\hline
\end{tabular}

\begin{tabular}{|l|l|l|l|l|l|}
\hline Inst.7 & 15 & 6 & 9 & 9 & 9 \\
\hline
\end{tabular}

The setup time for OR and surgeons is $\mathrm{tr}=\mathrm{ts}=15 \mathrm{~min}$. For all ORs and all surgeons the regular operating time RAT $=$ RATS $=480 \mathrm{~min}$. For the $\mathrm{CP}$ model, the duration of the time slot is set to $15 \mathrm{~min}$, thus creating 32 daily time periods in regular working time, whilst overtime is not provided for planning.

\section{A. The comparaison of the two models}

Table V summarizes the computational performance of the two models. The first column lists the number of the instances. The columns Variables and Constraints represent respectively, the number of variables and constraints in the two models. The Obj column shows the optimal objective value found when the program is terminate; and the CPU column is the computational time (in seconds) when the optimal solution is obtained. The performance of the two models is compared from four aspects. The results are shown in Table V. As we can see, the MILP model is efficient to solve the operation scheduling problem. Both the number of variables and constraints of the MILP model are smaller than the CP model. Partially due to the smaller number of constraints and variables, the MILP model is solved faster and can make the optimal solution compared with the CP model. For all instance, the MILP model is able to find the optimal solution in a reasonable time for this problem; in average the CPLEX solver take 700 seconds ( 11 minutes) to find the optimal solution.

We show that the optimal solutions found by the CP model are the same with the ones obtained by the MILP model. Nevertheless, if we look at the CPU time to obtain the optimal solution, we notice that the $\mathrm{CP}$ proves more computational times than the MILP model. We also notice that the more the instance has a large number of constraints, the more the values of the time computing is increase, which is normal. This shows us that the $\mathrm{CP}$, when there is a large number of constraints, takes advantage of the parceling of the search space.

In this section, we compare an exact method (MILP) by an approximate method (CP). We push the CP model to find the optimal solution to compare with the MILP model in terms of computational times. We notice that The $\mathrm{CP}$ model uses more time to find an optimal solution unlike the MILP model which finds the optimal solution in a reasonable time. Therefore, to our problem, The MILP approach is sufficiently efficient to propose optimal solutions in a very short time and an approximately approach is not necessary.

\section{B. The impact of the new structure of $O T$}

In this section we compare two scheduling strategies: in the first, we assume that the induction of operation is performed in the OR. In the second strategy, the induction of operation is performed in the induction bed.

To test the two strategies, we use the problem instance $n^{\circ} 3$ where there are four ORs, six induction beds, six recovery beds and four nurses. The problem instance includes 13 operations performed by six surgeons over single day. In strategy 1 , the Makespan is 525 minutes and in the second the Makespan is 450 minutes. We notice that in the first strategy we have 45 minutes overtime and with the new structure the Makespan is 
reduced and all operations are scheduled in a regular time of OT.

Fig. 1. Charge of ORs in these two strategies

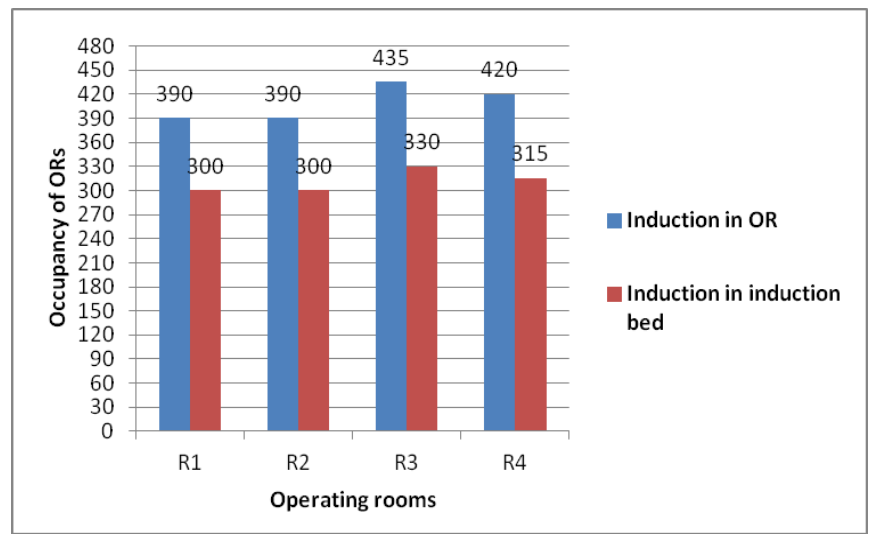

We can see in fig. 1 , when the induction is performed in the induction bed, the occupancy of the ORs is reduced. In this case we can add other operations in the daily planning and we can maximize the occupancy rate of ORs. Therefore the economic profit of OR can increase.

\section{CONCLUSION}

In this study, we present a MILP model for OR scheduling problem. This model takes into account the material (induction beds, ORs and recovery beds) and human (surgeons and nurses) resources. The main contribution of the paper is to solve the allocation and sequenced phases in the same problem and to perform the induction of operation in the induction bed.

To prove the efficiency of MILP model to solve the scheduling problem, we develop a $\mathrm{CP}$ model. These two models are evaluated using several problem instances and we push the $\mathrm{CP}$ model to find the optimal solution. The results show that the MILP model is more efficient than the CP model in terms of computational times. Thus, for this problem, the exact method is sufficiently efficient to find optimal solutions in a reasonable time.

To analyze the impact of the new structure of the OT, we compare two strategies scheduling: induction of operation is performed in the ORs or in the induction bed. According to the results, we show that with the new structure of the OT, the occupancy of the ORs is reduced which we can increase the number of planned operations in the planning day and maximize the occupancy rate of the ORs.

In this paper, we study the daily scheduling problem in a deterministic context. In the future work, it is necessary to take into accounts the urgent operations and to evaluate the robustness of the MILP model. Other suggestion for future research is to extend the proposed models by including other human resources such as the porters and the anesthetists.

\section{REFERENCES}

[1] V. Augusto, X. Xie and V. Perdomo, Operating theatre scheduling with patient recovery in both rooms and recovery beds, Computer \& Industrial Engineering., vol. 58, pp.231-238, 2010.

[2] H. Ghazalbash, M.M. Sepehri, P. Shadpour and A. Atighehchian, Operating room scheduling in teaching hospitals, Advances in Operation Research, vol. 2012, 2012.

[3] A. Jebali, A. Hadj Alouane and P. Ladet, Operating rooms scheduling, International Journal of Production Economics, vol. 99, $\mathrm{N}^{\circ} 1-2$, pp. $52-$ 62, 2006.

[4] A. Hanset, N. Meskens and D. Duvivier, Using constraint programming to schedule an operating theatre, Health Care Management (WHCM), IEEE Workshop, pp.1- 6, 2010

[5] E. Koksalmis, K.O. Hancerliogullari and G. Hancerliogullari, How to schedule surgical operations into operating rooms? An application in Turkey, Industrial and systems Engeneering Research Conference Montréal Canada, pp. 1139-1148, 2014.

[6] F. Maaroufi, H. Camus and O. Korbaa, A VSCP approach for solving the operating theater scheduling problem, the first international conference on Reasoning and Optimization in Information Systems (ROIS'2013) Hamam Sousse Tunisia, DOI: 10.13140/2.1.4864.3363, pp.57-64, 2013.

[7] I. Marques, M.E. Captivo and M. Vaz Pato, An interger programming approach to elective surgery scheduling, OR Spectrum, vol. 34, pp. 407427,2012

[8] N. Meskens, D. Duvivier and A. Hanset, Multi-objective operating room scheduling considering desiderata of the surgical team, Decision Support Systems, vol. 55, pp. 650-659, 2013.

[9] D.N. Pham and A. Klinkert, Surgical case scheduling as a generalized job shop scheduling problem, European Journal of Operational Research, vol. 185, pp. 1011-1025, 2008.

[10] A. Roberto, L.Paolo, S.Patrick, T.Elena, T. Angela, A two level metaheuristic for the operatig room scheduling and assignement problem, Computers\& Operation Research, vol. 54, pp.21-34, 2015.

[11] B. Roland, C.D. Martinelly, F. Riane and Y. Pochet, Scheduling an operating theatre under human resource constraints, Computer \& Industrial Engineering journal, vol. 58, pp. 212-220,2010.

[12] Z. Zaho and X. Li, Scheduling elective surgeries with sequencedependent setup times to multiple operating rooms using constraint programming., Operations Research for health care, vol. 3, pp. $160-$ 167,2014

TABLE V. THE COMPUTATIONAL PERFORMANCE OF THE TWO MODELS

\begin{tabular}{|l|l|l|l|l|l|l|l|l|}
\hline & \multicolumn{4}{|c|}{ MILP model } & \multicolumn{4}{c|}{ CP model } \\
\hline $\begin{array}{c}\text { Instances } \\
\boldsymbol{N}^{\circ}\end{array}$ & variables & constraints & $\begin{array}{c}\text { Obi } \\
(\mathbf{m i n})\end{array}$ & $\boldsymbol{C P U}(\mathbf{s})$ & variables & constraints & $\begin{array}{c}\text { Obi } \\
\text { (time } \\
\text { slots) }\end{array}$ & $\boldsymbol{C P U}(\mathbf{s})$ \\
\hline Inst.1 & 1935 & 4436 & 315 & 4.93 & 7488 & 12160 & 21 & 3202.15 \\
\hline Inst.2 & 2854 & 6626 & 375 & 125.74 & 9152 & 14230 & 25 & 7355.21 \\
\hline Inst.3 & 3953 & 9256 & 450 & 1378.28 & 10816 & 16280 & 30 & 11058.7 \\
\hline Inst.4 & 5232 & 12318 & 480 & 975.32 & 12480 & 18340 & 32 & 14961.51 \\
\hline Inst.5 & 4232 & 9982 & 315 & 23.51 & 13728 & 22833 & 21 & 16541.22 \\
\hline Inst.6 & 5863 & 13935 & 330 & 960.33 & 16224 & 25917 & 22 & 22547.1 \\
\hline Inst.7 & 7762 & 18548 & 375 & 1391.25 & 18720 & 29001 & 25 & 31047.85 \\
\hline
\end{tabular}

